\title{
Latent learning in rats with hippocampal lesions
}

\section{LARRY W. MEANS, University of Florida, Gainesville, Fla. 32601}

Six of 12 hippocampally lesioned and 5 of 11 cortically lesioned rats were given 16 nondeprived exposure trials in a T-maze prior to acquisition of a spatial discrimination. The remaining $S s$ in each lesion group were given no preacquisition maze exposure. $S s$ in both lesion groups who were given preacquisition maze exposure required fewer trials to acquire the discrimination.

Recently, Kimble \& Green (1968) found that hippocampally lesioned rats, given four 5 -min nondeprived exposure trials in a Lashley III maze prior to acquisition, failed to show a reduction in errors during subsequent training, whereas this exposure did produce a reduction for normal and cortically lesioned animals. However, several considerations suggest that the procedures employed by these investigators were less than optimal for the occurrence of latent learning in hippocampectomized Ss. One, Kimble and Green suggest that, due to attentional deficits, hippocampally lesioned Ss may need more maze exposure than control Ss. Possibly the 20-min exposure that Kimble and Green gave their Ss was insufficient for hippocampectomized Ss to demonstrate latent learning in their situation. Two, it is well known that hippocampally lesioned Ssperseverate established responses (Jarrard, Isaacson, \& Wickelgren, 1964; Niki, 1962). Possibly the freeexposure period employed by Kimble and Green was sufficient for hippocampally lesioned Ss to establish "erroneous response patterns" that were then perseverated during acquisition. Finally, it is well known that hippocampally lesioned rats show large deficits on acquisition in a Lashley III maze when compared to cortically lesioned controls and normals (Madson \& Kimble, 1965; Niki, 1962). It would seem that hippocampectomized Ss would be more likely to show latent learning on a task that they learn as readily as control animals. The present study was an attempt to demonstrate latent learning in hippocampally lesioned Ss under more optimal circumstances.

\section{METHOD}

Twenty-three adult male Long-Evans rats were employed as Ss. Twelve rats sustained bilateral aspiration lesions of the hippocampus and overlying cortex and 11 sustained bilateral aspiration lesions of the overlying posterolateral cortex. The lesion procedure was essentially the same as that employed by Isaacson, Douglas, \& Moore
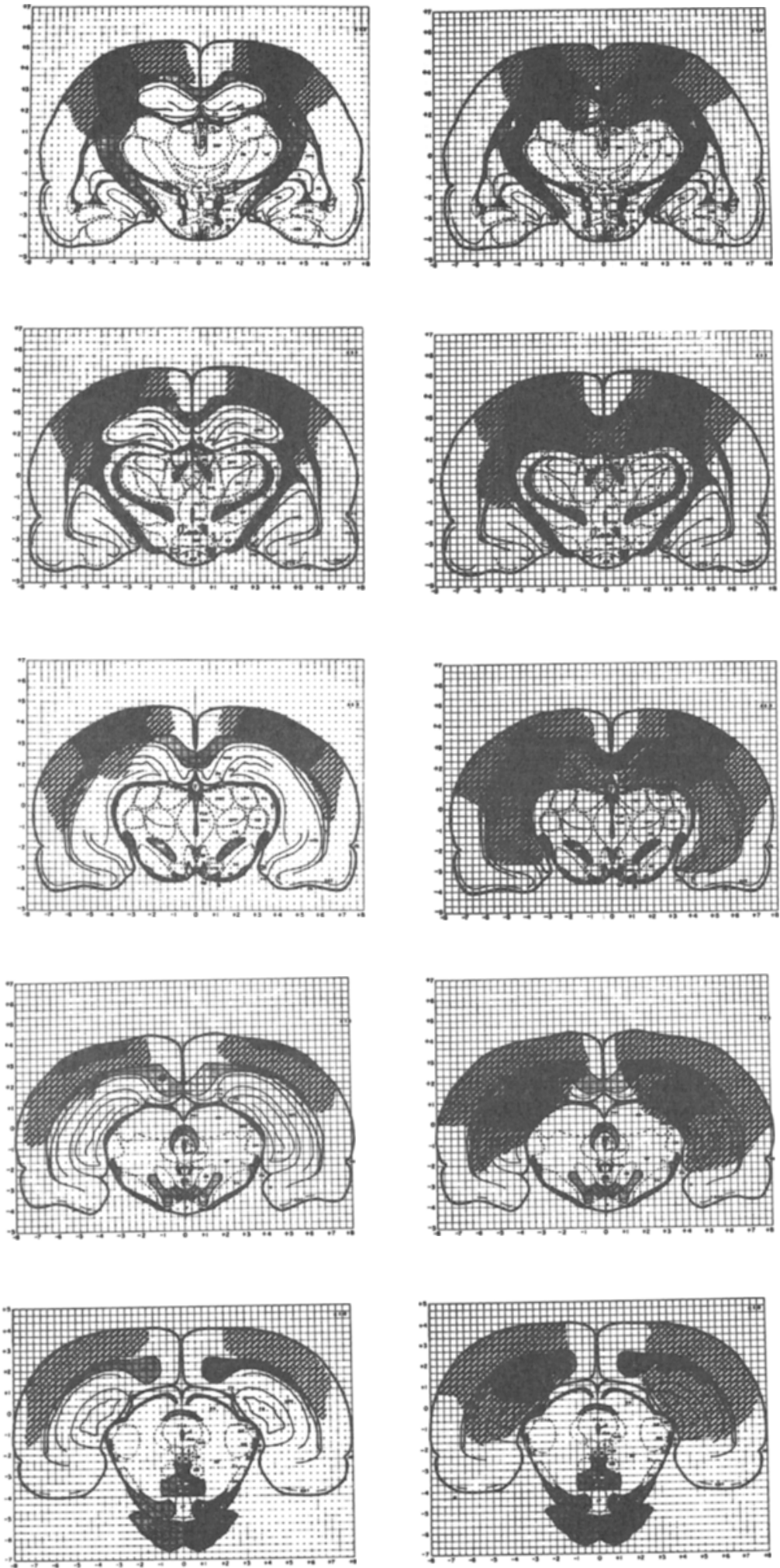

Fig l. Reconstructions of the largest and smallest extent of the lesions. The cortical control Ss are on the left, and the hippocampally lesioned Ss are on the right. 
(1961). Reconstructions of the largest and smallest lesions for both lesion groups are shown in Fig. 1.

The apparatus was a gray painted cap T maze. The maze had a 6-in.-long startbox, a 4-in. alley approaching the choice-point, and $12 \frac{1}{2}$-in.-long choice arms. All sections were 5 in. wide and 6 in. deep. The entire maze was covered with $1 / 4$-in. hardware cloth. Guillotine doors separated the startbox and goal arms from the choice-point. The goal arms had a short elbow extending toward the startbox.

Pretraining was initiated for all Ss 14 days after surgery. The animals were placed in groups of six on a table top and handled by $E$ for approximately $20 \mathrm{~min}$ each day for 5 days. Next, the Ss were given 5 days of food-cup training which involved allowing the animals, while under 23-h food deprivation, to eat four Noyes .045 -g pellets from each of two metal bottle caps randomly placed on the table. The Ss were handled constantly while being trained to eat out of the food cups. Upon completion of food-cup training all $\mathrm{Ss}$ showed no emotional reaction to handling and would immediately run to a food cup and consume the pellets when placed on the table.

Upon completion of pretraining one-half of the $\mathrm{Ss}$ in each lesion group were given 2 days (eight trials per day) of nondeprived exposure trials before acquisition training. While 16 exposure trials probably involved less actual exposure time than the $20 \mathrm{~min}$ given by Kimble and Green, it was felt that 16 trials would be sufficient exposure for a simple T-maze discrimination. The remaining $\mathrm{Ss}$ in each group were given acquisition trials without prior exposure. The only difference between exposure and acquisition trials was that Ss were not deprived during exposure trials and were 23 -h food deprived during acquisition trials. During both acquisition and exposure, Ss were given eight trials a day, with odd-numbered trials being free-choice trials and even-numbered trials being forced choice. On the forcedchoice trials, the door to the goal arm selected by the rat on the preceding free-choice trial was closed, forcing the rat to enter the opposite goal arm. The forced-trial procedure was employed to prevent the development of a perseverated response to one of the alleys and to insure equal exposure to both arms. A food cup

Table 1

Mean Free Choice Trials and Mean Errors to Criterion for Hippocampally and Cortically Lesioned Rats

\begin{tabular}{llcc}
\hline $\begin{array}{l}\text { Dependent } \\
\text { Variable }\end{array}$ & $\begin{array}{l}\text { Lesion } \\
\text { Group }\end{array}$ & $\begin{array}{c}\text { No-Maze } \\
\text { Exposure }\end{array}$ & $\begin{array}{c}\text { Maze } \\
\text { Exposure }\end{array}$ \\
\hline $\begin{array}{llcc}\text { Free-choice trials } \\
\text { to criterion }\end{array}$ & Hippocampal & 5.83 & 3.33 \\
\hline Cortical & 4.33 & .80 \\
\hline $\begin{array}{l}\text { Errors to } \\
\text { criterion }\end{array}$ & Hippocampal & 3.33 & 2.50 \\
\hline
\end{tabular}

containing four Noyes pellets was placed in the elbow of the correct arm on all exposure and acquisition trials. The reward was placed in the right goal arm for one-half of the Ss and in the left arm for the other half. A noncorrection procedure was employed and the intertrial interval was approximately $12 \mathrm{~min}$. Ss were held in the goal arm for $15 \mathrm{sec}$ or until the food was consumed. Only once did a nondeprived $S$ eat any of the pellets. All Ss were trained to a criterion of 9/10 correct choices on 10 free-choice trials. RESULTS AND DISCUSSION

The mean number of free-choice trials and the mean number of errors to criterion for all groups is shown in Table 1. Ss in both lesion groups who received maze exposure required on the average fewer free-choice trials to reach criterion than did the nonexposed Ss. This was shown by a lesion by exposure vs nonexposure analysis of variance performed on the number of deprived free-choice trials to criterion which produced only a significant exposure effect $(F=5.47, \mathrm{df}=1 / 19, \mathrm{p}<.05)$. The same analysis performed on the number of errors to criterion revealed no significant effect. However, observation of Table 1 reveals that Ss receiving maze exposure did make slightly fewer errors than Ss not given maze exposure. Possibly, the failure to find a significant reduction is due to a ceiling effect. So few errors are made in learning a spatial discrimination that there is little chance for improvement following expo sure. Thus, it appears that both cortically and hippocampally lesioned Ss are capable of latent learning, at least in terms of the number of motivated trials to criterion.

Any maze task involves at least two types of learning, general habituation to the maze and acquisition of the specific response. Muenzinger \& Conrad (1953) have shown that both types of latent learning occurs with normal Ss when sufficient maze exposure is given, but that only habituation occurs when less maze exposure is given. The latent learning observed in the present experiment was largely restricted to general habituation to the maze. This is shown by the fact that exposed Ss did not choose the correct arm on the first deprived acquisition trial more frequently than would be expected by chance. Only 5 of 11 exposed Ss made the correct choice on the first acquisition trial.

The present study differs from that of Kimble and Green in so many ways that the two studies should not be viewed as being inconsistent. In fact, both studies failed to find a reduction in errors following maze exposure. However, from the present study, it is clear that under the appropriate conditions, hippocampectomized Ss can benefit from maze exposure in terms of trials to criterion.

\section{REFERENCES}

ISAACSON, R. L., DOUGLAS, R. J., \& MOORE, R.Y. The effect of radical hippocampal ablation on acquisition of an avoidance response. Journal of Comparative \& Physiological Psychology, $1961,54,625-628$.

JARRARD, L. E., ISAACSON, R. L., \& WICKELGREN, W. O. Effects of hippocampal ablation and intertrial interval on runway acquisition and extinction. Journal of Comparative \& Physiological Psychology, 1964, 57 , 442-444.

KIMBLE, D. P., \& GREENE, E. G. Absence of latent learning in rats with hippocampal lesions. Psychonomic Science, 1968, 11,99-100.

MUENZINGER, K. F., \& CONRAD, D. G. Latent learning observed through negative transfer. Journal of Comparative \& Physiological Psychology, 1953, 46, 1-8.

NIKI, $H$. The effects of hippocampal ablation on the behavior in the rat. Japanese Psy chological Research, 1962, 4, 139-153. NOTE

1. This work was conducted at Claremont Graduate School, Claremont, California. The author wishes to thank Dr. Robert L. Isaacson for his assistance in preparing this report, and Mrs. Pauletta Sanders for her assistance with the histology. 